IZA DP No. 5431

Effects of Adult Education Vouchers on the Labor Market: Evidence from a Randomized Field Experiment

Guido Schwerdt

Dolores Messer

Ludger Woessmann

Stefan C. Wolter

January 2011 


\title{
Effects of Adult Education Vouchers on the Labor Market: Evidence from a Randomized Field Experiment
}

\author{
Guido Schwerdt \\ Ifo Institute and CESifo \\ Dolores Messer \\ University of Bern
}

Ludger Woessmann

University of Munich, Ifo Institute, CESifo and IZA

Stefan C. Wolter

University of Bern, CESifo and IZA
Discussion Paper No. 5431
January 2011

IZA

P.O. Box 7240

53072 Bonn

Germany

Phone: +49-228-3894-0

Fax: +49-228-3894-180

E-mail: iza@iza.org

Any opinions expressed here are those of the author(s) and not those of IZA. Research published in this series may include views on policy, but the institute itself takes no institutional policy positions.

The Institute for the Study of Labor (IZA) in Bonn is a local and virtual international research center and a place of communication between science, politics and business. IZA is an independent nonprofit organization supported by Deutsche Post Foundation. The center is associated with the University of Bonn and offers a stimulating research environment through its international network, workshops and conferences, data service, project support, research visits and doctoral program. IZA engages in (i) original and internationally competitive research in all fields of labor economics, (ii) development of policy concepts, and (iii) dissemination of research results and concepts to the interested public.

IZA Discussion Papers often represent preliminary work and are circulated to encourage discussion. Citation of such a paper should account for its provisional character. A revised version may be available directly from the author. 
IZA Discussion Paper No. 5431

January 2011

\section{ABSTRACT \\ Effects of Adult Education Vouchers on the Labor Market: Evidence from a Randomized Field Experiment ${ }^{*}$}

Lifelong learning is often promoted in ageing societies, but little is known about its returns or governments' ability to advance it. This paper evaluates the effects of a large-scale randomized field experiment issuing vouchers for adult education in Switzerland. We find no significant average effects of voucher-induced adult education on earnings, employment, and subsequent education one year after treatment. But effects are heterogeneous: Loweducation individuals are most likely to profit from adult education, but least likely to use the voucher. The findings cast doubt on the effectiveness of existing untargeted voucher programs in promoting labor market outcomes through adult education.

JEL Classification: $\quad$ I22, J24, H43, C93, M53

Keywords: field experiment, voucher, adult education, LATE, Switzerland

Corresponding author:

Ludger Woessmann

ifo Institute for Economic Research

at the University of Munich

Poschingerstr. 5

81679 Munich

Germany

E-mail: woessmann@ifo.de

\footnotetext{
* We are grateful to participants at the CESifo area conference on Economics of Education in Munich, in particular Eric Bettinger, seminars at the universities of Basel and Frankfurt, the Institute of Education at the University of London, and the Ifo Institute, the annual congress of the German Economic Association in Kiel, and the Marbach conference on Evidence-Based Educational Policy for helpful comments. We would like to thank the Swiss Federal Office for Professional Education and Technology for financial support and the Swiss Federal Statistical Office for logistic support in conducting the experiment. We are also grateful for the opportunity to utilize the data of the Swiss Labor Force Survey.
} 


\section{Introduction}

Governments in most countries support lifelong learning by intervening in the adult education market, using such mechanisms as tax subsidies, grants, loans, and subsidies to providers (OECD, 2004, 2005). Recently, several countries have introduced voucher programs to stimulate adult education. ${ }^{1}$ Vouchers are intended to increase the demand for adult education by reducing its direct cost while at the same time enhancing individuals' ability to exercise choice in the education market. However, little is known about the returns to adult education or the effectiveness of government attempts to promote adult learning. From a theoretical viewpoint, government intervention in the adult education market can be justified if market failures such as liquidity constraints, externalities, or imperfect information about private returns lead to suboptimal private investment in adult education (see McCall and Smith 2009 for an overview). In such cases, public support for adult education should materialize in better labor market outcomes. On the other hand, government investment might be less effective in adult education than in early education (Cunha and Heckman, 2007). Any attempt to quantify the effects of adult education vouchers faces the fundamental problem of selection bias, because adults choosing to participate in education are likely to differ from adults choosing not to participate in many ways related to labor market success.

This paper evaluates the labor market effects of a large-scale randomized field experiment that provided vouchers for fee-based adult education courses to a representative sample of the adult population in Switzerland. In the experiment, which we designed specifically for this purpose, a random sample of participants in the Swiss Labor Force Survey (SLFS), first observed in 2005, was issued a voucher that could be redeemed for adult education courses in the first half of 2006. We exploit the exogenous variation generated by random assignment of the voucher to identify causal effects of the voucher treatment on earnings, employment status, and subsequent participation in adult education in $2007 .{ }^{2}$ In our estimation sample of more than 10,000 individuals observed from 2005 through 2007, the treatment group consists of 1,422 individuals, which we can compare to a control group of 9,099 individuals who did not receive the voucher offer. By making use of SLFS respondents and not releasing public information on the experiment, our setup ensured that neither treatment nor control group were aware of being part of an experiment, precluding Hawthorne effects.

\footnotetext{
${ }^{1}$ In particular, education voucher models are provided by the regional chambers of trade in Austria, the Training Check in Belgium, adult education vouchers in several Italian regions, the North Rhine-Westphalian and Brandenburg Training Check in Germany, and the Training Check in the canton of Geneva in Switzerland.

${ }^{2}$ The 2006 data of the experiment have been used to analyze pick-up rates and deadweight losses in Messer and Wolter (2009). Extension to the 2007 data allows us to evaluate effects on labor market outcomes.
} 
The overall voucher effect is determined by the rate at which vouchers are picked up in the treatment group and by the effect of voucher-induced adult education on labor market success. The latter effect might differ from non-experimental estimates of the effects of adult education, which will be biased if selection into adult education is driven by non-ignorable unobserved characteristics. In addition, individuals who comply with the voucher assignment by picking up the voucher may have non-average returns to adult education. We investigate this by comparing OLS estimates of the returns to adult education with IV estimates that use voucher receipt as an instrument for adult education. Moreover, we investigate potential heterogeneous effects of adult education and voucher receipt on labor market success for selected sub-groups of the population. We characterize the complier population in terms of these selected characteristics, which is valuable from a policy perspective as it describes the population actually affected by a voucher policy.

We find no statistically significant average effects of voucher-induced adult education on earnings and employment probabilities one year after treatment. While limited precision of our IV estimates does not allow us to statistically reject the existence of small positive effects, our IV point estimates suggest substantially lower returns to voucher-induced adult education than those suggested by OLS estimates. Analyzing the potential effect of the voucher on subsequent adult education, we can exclude the possibility that the large persistence in adult education implied by OLS estimation, even after controlling for past outcomes, is causal. Small positive effects of voucher-induced adult education on continuing human capital investments cannot be excluded and are in fact suggested by the IV point estimates.

The results highlight the importance of selection problems when estimating returns to adult education. Our results suggest that the incidence of and returns to adult education vary significantly between sub-populations. Our estimates of the returns to voucher-induced adult education thus likely identify a particular local average treatment effect (LATE). In this particular case, however, obtaining an estimate for the LATE parameter of voucher-induced adult education is even more relevant from a policy perspective than estimating an average treatment effect on the treated (ATT) of adult education, because only the former captures what is achievable by a voucher policy. By comparing first-stage coefficients for specific subgroups to the overall first-stage coefficient, we can characterize the population of compliers. The results indicate that individuals with higher levels of education are more likely to comply with the voucher assignment, while individuals with low levels of education are less likely to comply. A sub-group analysis of labor market effects suggests, however, that individuals with vocational training have a relatively high potential to benefit from participation in adult 
education. This substantial effect heterogeneity is a likely source for the statistical imprecision of our IV estimates of the average effect. An adult education voucher might entail significant labor market effects when targeted at specific sub-groups. Our findings cast doubt, however, on the effectiveness of untargeted voucher programs, as currently devised in many countries, to promote labor market outcomes through adult education. The same is likely to apply to the tax credit programs for education expenditures for adults as currently implemented in many countries, which are effectively untargeted as well.

While providing the first experimental evidence on labor market effects of an adult education voucher program aimed at the full adult population, our study adds to a large, albeit mostly non-experimental literature on labor market effects of adult education and training (see McCall and Smith 2009 for a review). There are three strands of this literature. The first one addresses the labor market returns to private on-the-job training within firms (e.g., Barron, Black, and Berger, 1997; Bassanini et al., 2005; Frazis and Loewenstein, 2005; Booth and Bryan, 2005). It seems fair to say, though, that most of the literature on earnings effects of workplace education and training, provided and mostly financed by firms, is far less developed in terms of causal identification than the literature on earnings effects of general education (see Card, 1999). For example, by restricting the comparison group to individuals who were kept out of training by arguably random events, Leuven and Oosterbeek (2008) show that selection-correction and fixed-effects strategies usually employed in the literature are likely to remain subject to substantial selection bias.

A second strand of existing literature that is not confined to firm-financed education estimates labor market effects of formal education for adults. Again based on observational data, studies in this literature focus on topics like the effects of upper-secondary or college attendance for returning adults (e.g., Leigh and Gill, 1997; Stenberg, 2011; de Luna, Stenberg, and Westerlund, 2011), often with a particular focus on displaced workers (e.g., Jacobson, LaLonde, and Sullivan, 2005; Stenberg and Westerlund, 2008).

A third and large strand of literature focuses almost exclusively on the sub-population of unemployed people when estimating labor market impacts of public-sector job training as a means of active labor market policy. Some of these studies evaluate randomized social experiments (for surveys and meta-analyses, see, e.g., Heckman, LaLonde, and Smith, 1999; Card, Kluve, and Weber, 2010). The vast majority of studies employs elaborate nonexperimental identification techniques to estimate the labor market impacts of public programs aimed at the unemployed (see Heinrich et al., 2009 and Lechner and Wunsch, 2009 for recent examples of evidence from the United States and Europe, respectively). Still, as is 
duly acknowledged in this literature, it is hard to ultimately rule out selection bias in such observational studies, and comparison to experimental evidence has shown that econometric evaluations of training programs can lead to very misleading results (see LaLonde, 1986).

Our study aims to extend the existing literature both methodologically and content-wise. Methodologically, we try to overcome remaining issues of selection into adult education by devising a randomized field experiment. ${ }^{3}$ In terms of content, there is a clear gap in the literature regarding public subsidization of self-financed education programs aimed at the adult population at large, in contrast to firm-financed adult education and to the population of unemployed. Despite the fact that governments in several countries have implemented general voucher and tax credit programs for adult education, there is hardly any evidence on the labor market effects of such untargeted programs. On public interventions, the literature strongly emphasizes active labor market policies with samples restricted to unemployed. On more general adult education programs, the literature strongly emphasizes firm-financed education. Our study provides first experimental evidence on the effect of government-sponsored selffinanced adult education for a sample representative of the entire population, thereby adding to the literature on designing public policies to promote adult education.

The remainder of the paper is structured as follows. The next Section describes the largescale randomized field experiment designed to offer vouchers for adult education. Section 3 reports descriptive evidence. Section 4 presents the estimation strategy and Section 5 the estimation results. Section 6 concludes.

\section{The Experiment}

The voucher experiment was initiated in 2005, when the Swiss government mandated a randomized field experiment with vouchers for adult education in order to investigate whether general voucher programs could increase adult education and improve labor market outcomes. In designing the experimental setup, we took advantage of the fact that the sample population of the Swiss Labor Force Survey (SLFS) had been raised significantly at the beginning of the century, but was scheduled to be reduced in 2006 because of financial constraints. The SLFS

\footnotetext{
${ }^{3}$ While there are few large-scale randomized experiments of public voucher programs in general, an example of an exception is the random lottery of housing vouchers in the Moving to Opportunity program (see Kling, Liebman, and Katz, 2007). In this regard, our study extends the experimental literature to public voucher programs subsidizing adult education. There is also an experimental literature on the effects of vouchers to attend private schools (e.g., Rouse, 1998; Peterson et al., 2003) which focuses on lotteries of oversubscribed programs to subsidize attendance of private schools, but the extent to which evidence from oversubscribed samples generalizes to the total population - or from school children to adult population - is unclear. See Greenberg and Shroder (2010) for social experiments conducted in other areas and Harrison and List (2004) for an overview of field experiments in economics.
} 
is structured according to a rotating panel principle in which the respondents are interviewed for five consecutive years. As a result, about one-fifth of the respondent population is replaced every year. The financially induced reduction in the sample population in 2006 yielded the opportunity to select a random sample of 2,437 individuals for the experiment who had been interviewed in the 2005 SLFS and would normally have been scheduled to continue participating in the next round of interviews but would have been dropped for financial reasons if our experiment had not funded their continuing participation.

The treatment group is matched by a control group of 17,234 individuals who had been interviewed by the SLFS in 2005 and were scheduled to be interviewed again in 2006. The experimental design enables us to use longitudinal data as well as cross-sectional information, among others on prior labor market outcomes and prior participation in adult education. This pre-experimental data allow us to check the experimental design and control for preexperimental labor market and adult education status.

The only limitation that we imposed on the sample refers to age. Only individuals aged 20 to 60 were entitled to receive a voucher. Most under-20s would still be undergoing education or training, and a large share of over-60s would be likely to be retired pensioners. There were no limitations with respect to employment status, as increasing the skills of non-employed individuals may be a goal of the voucher policy.

The 2,437 randomly selected individuals received a letter from the Swiss Federal Statistical Office during the first days of January 2006 containing the adult education voucher. The letter stated that the voucher was part of a project to promote lifelong learning by the Federal Office for Professional Education and Training and that participants of the SLFS were particularly well suited to receive this gift. The letter was signed by the General Director of the Swiss Federal Statistical Office to eliminate any doubts about the legitimacy of the voucher. No public-domain information was generated at any point during the experimental period, to ensure that voucher recipients were unaware that the dispensing of the voucher was part of an observational study. There were vouchers of three different face values (worth 200, 750 , and 1,500 Swiss francs, respectively - one Swiss franc being roughly equivalent to one U.S. dollar), allocated randomly among the treatment group. ${ }^{4}$

Recipients were entitled to use the voucher for an adult education course of their choice. The adult education program had to start in July 2006 at the latest. There were no restrictions

\footnotetext{
${ }^{4}$ In addition, half of the treatment group received an accompanying offer for free counseling. In our analyses, we did not find any significant differences in estimated effects between those who were offered counseling and those who were not.
} 
on the content of the adult education module because the intention was to use the choices as the basis for designing an efficient adult education voucher system later on. Subsequent inspection of course choices reveals that only 10.0 percent of those who picked up the voucher used it for course types that might broadly fall within the category of leisure courses. The largest category, at 39.7 percent, is courses that are directly job-related, followed by foreign language courses at 28.4 percent and IT courses at 21.0 percent. The vast majority of vouchers were thus used for adult education courses that might be seen as labor market relevant. ${ }^{5}$ The average duration of the adult education courses chosen by those who picked up the voucher was 42 hours.

Of the total of 2,437 voucher recipients, 449 redeemed their vouchers, representing a redemption rate of 18.4 percent. To redeem the voucher, participants had to send the voucher with the course organizer's invoice to the Federal Office for Professional Education and Technology, which in turn paid out the amount to participants. The federal agency conducted spot checks to verify that the adult education uptake and invoices were bona-fide. Though redemption rates were lower at the beginning and end of the redemption period, the overall temporal pattern of redemptions does not suggest any unintentional special effects. Toward the end of June, the experimental subjects were surveyed for the SLFS as in previous years. ${ }^{6}$

Like other adult education statistics, the SLFS differentiates between different forms of formal and informal adult education, and participation rates vary accordingly. The crucial aspect of government funding is its intention to raise opportunities for attending fee-based courses. Therefore, the selected SLFS module was the one that asked participants subsequently whether they had attended fee-based courses within the past twelve months.

\section{Descriptive Evidence}

This section provides descriptive statistics on several background characteristics and outcome variables. In 2007, the treatment and control groups were surveyed in the SLFS for the last time. All individuals of the original sample who were successfully interviewed in 2006 and 2007 constitute the estimation sample used in this analysis. Tables 1 and 2 report

\footnotetext{
${ }^{5}$ We experimented with estimating effects for the different course categories, but results did not differ significantly between categories. Similarly, qualitative results remained similar when dropping the leisure courses. Detailed results are available from the authors on request.

${ }^{6}$ To enable later linkage of the latter survey data with the experimental data, the participants were required at the end of the survey to say whether they consented to data linkage. This ensured both that the replies to the standard questions of the SLFS were not skewed because of linkage with the adult education voucher, while at the same time addressing data protection concerns. Fortunately, none of the respondents objected to linkage of the SLFS data with the experiment.
} 
selected average characteristics separately for the treatment and control groups for the years 2005 and 2007. ${ }^{7}$ The reported numbers of observations show significant panel attrition relative to the full sample surveyed in 2005. Among the treatment group, 77.5 percent took part in the SLFS at the end of June 2006. Of those participating in 2006, 76.3 percent again participated in the SLFS in 2007. Thus, 59 percent of the original treatment group is observed in 2007. This extent of panel attrition is standard in the SLFS. For comparison, 55 percent of the original control group is observed in 2007.

Table 1 shows that in most regards, the treatment group drawn randomly from the entire SLFS sample does not differ significantly from the control group. There are small, but statistically significant differences only for the criteria Swiss, vocational education, and university education. The education variables are associated with the nationality variable and the treatment and control groups do not differ statistically significantly if nationality is controlled for. We do not, however, have additional information why the groups differed with respect to the nationality of the survey respondents. What is important for the experiment is the fact that there was no possibility of survey respondents to influence the assignment to the treatment or control group.

Due to differences in response patterns, the difference between the treatment and control groups in the share of participants reporting to have attended adult education courses within the past 12 months in the 2005 survey, prior to the experiment, becomes marginally significant in the 2007 sample (Table 2). It seems that people active in adult education also have slightly higher response rates in the SLFS. Because the participation rate in adult education was higher in the treatment group, the significant difference appears in the 2007 sample. Due to the response difference, the significance of differences in educational characteristics shifts from the vocational to the compulsory and non-academic tertiary education categories in 2007. These observable differences caused by panel attrition and the initial over-assignment of vouchers to individuals with Swiss nationality emphasize the importance of controlling for these characteristics in the empirical analysis below.

To start with, Table 3 provides mean comparisons of outcome variables between the treatment and the control groups without controlling for any additional factors. The treatment group is 12.0 percentage points more likely to participate in fee-based adult education in the

\footnotetext{
${ }^{7}$ We use the terms treatment and control groups to refer to the experimental groups of voucher recipients and non-voucher recipients, although in the empirical analysis below the treatment effects we are interested in are in fact those of voucher-induced participation in self-financed adult education. The pattern of socio-demographic characteristics in 2006 (available from the authors on request), where the treatment group contains 1,888 individuals and the control group 14,193 individuals, is broadly consistent with the 2007 pattern.
} 
treatment year $2006 .{ }^{8}$ The inclusion of a specific adult education module in the 2006 wave of the SLFS allows us to distinguish between self-financed and firm-financed courses in 2006 (but not in the other years). Voucher recipients are 14.8 percentage points more likely to participate in self-financed adult education in 2006, reflecting the first-stage relationship between voucher receipt and participation in self-financed adult education that we exploit in our IV approach. At the same time, the share of individuals who participated only in firmfinanced adult education in 2006 is 2.8 percentage points lower in the treatment group, reflecting the fact that some individuals who without the voucher would have participated only in firm-financed training now additionally participate in self-financed courses. In the empirical analysis below, we therefore control for firm-financed training. ${ }^{9}$

The bottom part of Table 3 reports group means for our three outcome variables in 2007: gross hourly earnings, employment status, and participation in adult education. Gross hourly earnings are computed by dividing gross monthly earnings through effective hours worked. Employment status is a dummy variable indicating whether an individual was employed at the time of the survey. There are no significant mean differences in gross hourly earnings and employment probabilities in 2007 between the treatment group that was offered the voucher and the control group that was not. Figure 1 also provides kernel-density estimates of the distribution of gross hourly earnings for the treatment and control groups measured in 2005, 2006, and 2007. As the reported $p$-values from two-sample Kolmogorov-Smirnov tests of the equality of distributions indicate, we can reject the hypothesis that the wage distributions are different at any point.

Table 3 reveals, however, significant differences in the participation in adult education in 2007. Those who received a voucher in 2006 are 4.0 percentage points more likely to

\footnotetext{
${ }^{8}$ Note that there is a significant dip in reported participation rates in adult education in 2006 relative to previous and successive years that was a one-year event and concerned all groups of survey participants in a similar way. According to an official statement of the Federal Office for Statistics (http://www.bfs.admin.ch/bfs/ portal/de/index/themen/15/07/ind19.informations.190104.html), the dip is likely to reflect a change in the reporting behavior of survey respondents caused by a change in the sequencing and wording of questions due to the inclusion of the specific adult education module in the 2006 wave of the SLFS, rather than any real dip in overall participation in adult education. As these changes in the 2006 questionnaire affected the treatment and control groups in the same way, it does not raise concerns for our identification strategy.

${ }^{9}$ We use this definition of the firm training variable - which does not include individuals who have also participated in self-financed education - as it ensures that it does not capture indirect effects of the voucherinduced self-financed education to the extent that the latter might affect the effectiveness of the former. Applying an alternative definition of firm training by a dummy indicating participation in at least one firm-financed adult education course in 2006 does not affect the qualitative results of our empirical analysis. A comparison of means reveals no significant difference between the treatment and control groups in the probability of participating in at least one firm-financed adult education course in 2006, which we take as evidence that voucher receipt did not lead to significant substitution effects that decrease the incidence of firm training. Also, our results on selffinanced adult education below are qualitatively the same, with even lower point estimates, in specifications that do not control for firm training.
} 
participate in adult education in 2007, the year after the voucher redemption period. This could indicate a positive effect of voucher-induced participation in 2006 on subsequent private investments into adult education. However, Table 2 indicated that there were marginally significant differences in adult education participation between the treatment and control groups already before the experiment. This observation calls for a more rigorous analysis of the effects of voucher-induced adult education.

\section{Empirical Strategy}

We are interested in the effect of the adult education voucher on subsequent labor market outcomes. The overall effect of the voucher is determined by the pick-up rate and by the effect of adult education on future labor market success. As seen above, voucher receipt positively affected immediate participation probabilities in adult education courses (see also Messer and Wolter, 2009). Pick-up rates are, however, relatively small. Whether the adult education voucher positively affects labor market outcomes, thus, crucially depends on the returns to adult education for those individuals who complied with the voucher assignment and used the offered voucher.

We therefore start by analyzing the effect of adult education on future labor market success. The following cross-sectional regression model is used to link labor market success to participation in adult education and a set of exogenous covariates:

$$
y_{i, t+1}=\beta \text { adult_education }_{i, t}+\alpha_{0}^{\prime} X_{i, t}+\varepsilon_{i, t},
$$

where $y_{i, t+1}$ is the outcome of interest for individual $i$ at time $t+1$, adult_education ad $_{i, t}$ is an indicator of (self-financed) adult education in $t, X_{i, t}$ is a vector of background characteristics measured at $t$, and $\varepsilon_{i, t}$ is an error term uncorrelated with all right-hand side variables. Note that our interest is in the effects of employee-financed adult education, with the help of a voucher. Because there is also firm-financed adult education and training, the control vector $X_{i, t}$ includes an indicator for firm-financed adult education. Our key parameter of interest is $\beta$, which measures the association between participation in self-financed adult education courses and labor market success in the subsequent period. However, in standard cross-sectional work, $\beta$ is likely to be a biased estimate of the effect of interest because participation in adult education is selective, partly in response to heterogeneity in the returns to adult education.

Longitudinal data can help to address part of the selectivity bias. We can exploit the panel structure of our data and include past outcomes in equation (1). The simplest way to do so 
would be to rewrite equation (1) in terms of a value-added model with first-differences in the outcome of interest as dependent variable. An alternative and less restrictive specification is to include past outcomes on the right-hand side of the equation. In this case, the equation of interest becomes:

$$
y_{i, t+1}=\beta \text { adult_education }{ }_{i, t}+\alpha_{0}^{\prime} X_{i, t}+\alpha_{1}^{\prime} X_{i, t-1}+\alpha_{2} y_{i, t-1}+\varepsilon_{i, t},
$$

where $X_{i, t-1}$ is a vector of labor market controls measured at $t-1$ and $y_{i, t-1}$ is the outcome of interest measured at $t-1$. The inclusion of past outcomes in the estimation should eliminate the confounding effect of time invariant individual characteristics that affect labor market outcomes. Yet, selection into adult education might not only be based on levels of observed or unobserved variables. For instance, if selection into self-financed adult education is driven by trends in the outcome variable, the estimate for $\beta$ in equation (2) provides biased estimates for the effect of interest.

The exogenous variation in adult education generated by the random assignment of the voucher in our experiment can be exploited to solve the endogeneity of self-financed adult education. As vouchers are assigned randomly, we can estimate a two-stage least-squares (2SLS) model with voucher receipt as instrument. In the just-identified model where voucher $_{i, t}$ is the only instrument for the endogenous variable adult_education ${ }_{i, t}$, the first-stage model relating voucher receipt to participation in adult education is:

$$
\text { adult_education }{ }_{i, t}=\gamma \text { voucher }_{i, t}+\pi_{0}^{\prime} X_{i, t}+\pi_{1}^{\prime} X_{i, t-1}+\pi_{2}^{\prime} y_{i, t-1}+\mu_{i, t} \text {, }
$$

where $\gamma$ is the first-stage effect of the instrument. The parameter corresponds to the pick-up rate of the voucher. The resulting IV estimate, $\hat{\beta}^{\mathrm{IV}}$, is an unbiased estimate for the average effect of self-financed adult education on labor market success for compliers. It identifies the local average treatment effect (LATE) for individuals who participate in adult education when receiving a voucher, but would not have participated if they had not received the voucher (Imbens and Angrist, 1994).

From a policy perspective, the parameter of interest is ultimately the effect of providing adult education vouchers on labor market outcomes. Because of random assignment of the vouchers in the field experiment, we can obtain an unbiased estimate of this effect by regressing indicators of labor market success on a dummy indicating voucher receipt. The reduced-form regression model is given by: 


$$
y_{i, t+1}=\phi \text { voucher }_{i, t}+\lambda_{0}^{\prime} X_{i, t}+\lambda_{1}^{\prime} X_{i, t-1}+\lambda_{2} y_{i, t-1}+\eta_{i, t}
$$

The parameter $\phi$ is the parameter of interest. It measures the effect of receiving an adult education voucher on the outcome of interest. Not every voucher recipient uses the voucher. The parameter therefore identifies an intention-to-treat (ITT) effect. Algebraically, it corresponds to the LATE estimate of the effect of adult education on labor market success, $\hat{\beta}^{\mathrm{IV}}$, scaled down by the pick-up rate estimated by the first-stage coefficient $\hat{\gamma}$.

\section{Results}

The discussion of the empirical results builds on the insight that returns to adult education are not constant in the population. We start by analyzing average labor market effects in the population. We then continue by investigating heterogeneous effects for sub-populations of interest. Finally, we characterize the sub-population that complies with the voucher assignment based on several background characteristics.

\subsection{Average Labor Market Effect of Adult Education Vouchers}

We investigate the effects defined in Section 4 based on three different labor market outcomes: hourly earnings, employment probabilities, and probabilities of subsequent participation in adult education. All outcomes are measured in 2007. Given that the voucher treatment took place in the first half of 2006, the results should be interpreted as estimates of short-run effects.

\subsubsection{Effects on Earnings}

We start by investigating effects on earnings. Earnings conditional on employment is the most obvious measure of labor market success. Inspired by the seminal work of Mincer (1974), a vast literature on the estimation of causal effects of education on earnings emerged (Card, 1999). Yet, the majority of studies focus on returns to schooling. The existing evidence on the returns to adult education is still thin. In particular, little evidence exists on the causal effect of self-financed adult education.

Table 4 displays estimation results with log gross hourly earnings in 2007 as dependent variable. The first four columns show results of OLS estimations based on equation (1) with different sets of covariates. In the first column, earnings are regressed on a dummy indicating participation in self-financed adult education in 2006, a dummy indicating participation in firm-financed adult education in 2006, a gender dummy, a dummy for Swiss nationality, and a 
linear and quadratic term in age. The results indicate positive associations of earnings with both self-financed and firm-financed adult education. The association between earnings and adult education is, however, stronger in the case of firm-financed education. This is in line with previous results in the literature suggesting significant positive effects of work-related training on earnings (e.g., Bassanini et al., 2005; Frazis and Loewenstein, 2005). Descriptively, participation in self-financed adult education is associated with 6.8 percent higher earnings and firm-financed education with 12.4 percent higher earnings in the following year. Both adult education coefficients, however, decrease when we additionally control for regional variation, family characteristics, and differences in language of the interview (column 2), as well as educational controls (column 3). In particular, the inclusion of indicators for the highest level of educational attainment reduces the coefficient on selffinanced adult education substantially. Overall, the results reveal the positive association between adult education and earnings typically found in the cross-sectional literature, but also indicate selective participation in adult education based on observable characteristics.

Column 4 of Table 4 shows estimates based on equation (2) which additionally controls for $\log$ gross hourly earnings in 2005 and other job characteristics measured in 2005, before the adult education measure. The results reveal that conditioning on past outcomes further reduces the estimate of the effect of self-financed adult education. The estimate suggests that after conditioning on these factors, participation in self-financed adult education is associated with 1.5 percent higher future earnings. The coefficient estimate is 5.3 percentage points lower compared to the estimated coefficient in column 1.

Does this estimate identify a causal effect? The OLS coefficient provides an unbiased estimate of the effect of adult education on earnings only if the selection-on-observables assumption holds, that is, if the included control variables perfectly determine participation in self-financed adult education. On the one hand, this seems reasonable as the specification estimated in column 4 of Table 4 includes a large set of covariates relevant for the decision to participate in adult education - much richer than commonly available in the literature. In particular, the specification includes past outcomes, thereby controlling for heterogeneity among individuals typically unobserved in the cross-section. Moreover, our data allow us to distinguish self-financed from firm-financed adult education. The results in column 4 show that this distinction matters. The coefficient on adult education financed by the employer is about twice as large as the coefficient on adult education paid by the individual. This is likely to reflect differences in the selection into these two types of adult education. On the other hand, selection into adult education might still be influenced by other unobserved factors. In 
particular, participation in self-financed adult education might be partly driven by expected earnings growth (Pischke, 2001). In this case, the estimate would still be biased.

In our experimental study, the random assignment of voucher offers a source of exogenous variation that we can exploit to identify the causal effect of self-financed adult education. Voucher receipt is a valid instrument for self-financed adult education: It satisfies the exogeneity assumption by construction and is also relevant.

The estimated first-stage model of the IV approach specified in equation (3) is reported in column 5 of Table $4 .{ }^{10}$ The estimated coefficient on the dummy variable indicating voucher receipt identifies the causal effect of the voucher on participation in adult education in 2006 . The coefficient of 0.11 corresponds to the pick-up rate of the voucher. It is lower than the redemption rate, because of the existence of always-takers. The estimate shows that receiving a voucher increases the probability to participate in an adult education course in 2006 by 11 percentage points. This effect is highly significant.

The last row of column 5 reports the Cragg and Donald (1993) minimum eigenvalue statistic (MES) as a test of weak instruments. Using weak instruments not only produces estimates with large standard errors, but can also lead to large inconsistencies of the IV estimates (Bound, Jaeger, and Baker, 1995). The minimum eigenvalue statistic is identical to the $F$-statistic on excluded instruments because the model contains only one endogenous regressor. Stock, Wright, and Yogo (2002) suggest that the F-statistic on excluded instruments must be large, typically exceeding 10 , for 2 SLS inference to be reliable when there is one endogenous regressor. A value of 61.5 clearly exceeds this threshold. However, Monte Carlo simulations show that simply looking at the $F$-statistic might not be sufficient (Hall, Rudebusch, and Wilcox 1996). A more formal test for weak instruments is provided in Stock and Yogo (2005), where critical values for worst-case rejection rates of 5, 10, 20, and 25 percent for nominal 5 percent Wald tests of the endogenous regressors are provided. In our case, the minimum eigenvalue statistic exceeds the critical value at all levels of significance. We can, thus, conclude that voucher receipt is not a weak instrument.

Column 6 of Table 4 shows the corresponding second-stage IV estimate of the effect of self-financed adult education on future earnings. The point estimate of -0.01 is small, negative, and statistically insignificant. This estimate is well below the estimate of the OLS specification. However, the standard error of the IV estimate is large, indicating that our IV

\footnotetext{
${ }^{10}$ We model the first stage as linear despite the binary nature of the outcome variable. Using a linear regression for the first-stage estimates generates consistent second-stage estimates even with a dummy endogenous variable (Angrist and Krueger, 2001).
} 
approach lacks precision. In particular, we cannot statistically reject the existence of effect sizes in the magnitude of the OLS coefficients. The lack of precision of the IV estimate results from the fact that there are many always-taker, and possibly also from substantial heterogeneity in the effect. However, the substantial reduction in the point estimate relative to the OLS results might still be economically important. The reduction in the estimated returns to adult education may have two reasons: First, OLS results are upward biased because individuals with favorable earnings growth predominantly select themselves into self-financed adult education, and this selection is not perfectly determined by the control variables included in equation (2). Second, considering the LATE interpretation of our IV approach, the IV estimate might measure the effect for a particular group of individuals with low returns to adult education in terms of future earnings.

From a policy perspective, we are ultimately interested in the causal effect of the voucher on future outcomes. Column 7 of Table 4 shows the estimation based on equation (4). The ITT effect is well identified because of the random assignment of the voucher. The point estimate is again negative, close to zero, and statistically insignificant. However, the standard errors are again somewhat large. We can only reject voucher effects larger than a one percent increase in earnings with 90 percent confidence.

\subsubsection{Effects on Employment}

Earnings are not the only meaningful indicator of labor market success. In a rigid labor market, effects of adult education might materialize more in terms of higher employment probabilities than in terms of increased earnings. Moreover, the earnings results are limited to continuously employed individuals. Participation in adult education might be particularly beneficial for the non-employed (Stenberg and Westerlund, 2008).

Table 5 therefore reports results for an indicator for employment in 2007. ${ }^{11}$ The structure of Table 5 resembles the structure of Table 4 and follows the empirical strategy laid out in Section 4. As, in contrast to the earnings equations of Table 4, here we do not condition on continuous employment, all estimations are based on the entire estimation sample. Consequently, we also do not include job characteristics in 2005 as covariates.

In the first three columns of Table 5, we estimate employment regressions based on equation (1) with different sets of controls. In column 4, we additionally control for employment status in 2005. The OLS estimates reveal the same picture as in the case of

\footnotetext{
${ }^{11}$ All estimations are based on linear models despite the binary nature of the outcome variable. We regard the OLS results as a linear approximation of the conditional expectation function of interest, as suggested in Angrist and Pischke (2009). Probit estimations produce almost identical results for the effects of interest.
} 
earnings: Self-financed adult education is positively associated with future employment probabilities. However, selection into adult education matters: As we increase the number of controls, the estimated associations of employment with both self-financed and firm-financed adult education decrease. Again, the effects for firm-financed adult education appear to be larger. Results displayed in column 4 indicate that adult education is related to 2.1 percentagepoints higher employment probabilities in 2007 in the case of self finance and to 3.1 percentage-points higher employment probabilities in the case of firm finance.

Columns 5 and 6 present results of estimating an IV approach with voucher receipt as instrument using 2SLS. ${ }^{12}$ Close to the first-stage estimation presented in Table 4, which is based on the reduced sample with continuously employed individuals, we find a causal effect of the voucher on self-financed adult education in 2006 of 12 percentage points (column 5). The IV estimate of the effect of self-financed adult education on employment probabilities in 2007 is close to zero (at 0.0001) and statistically insignificant (column 6). Standard errors are, however, again large and do not allow to reject the OLS estimates. Similar to the interpretation of the earnings results, the decrease in the point estimate relative to OLS still provides some indication that individuals complying with the voucher assignment might not experience any effect of adult education on future employment probabilities.

Column 7 reports the estimated ITT effect of voucher receipt on future employment probabilities. The point estimate is 0.00001 and not statistically significantly different from zero. The effect is, however, estimated with relatively low precision. The upper 90-percent confidence bound lies at 0.013 , which implies that we can reject positive effects exceeding a 1.3 percentage-point increase in future employment probabilities.

\subsubsection{Effects on Subsequent Adult Education}

So far, the focus has been on short-run effects of adult education. More precisely, we investigated the effects of participating in adult education in early 2006 on labor market success in 2007. While it seems reasonable to expect that participation in adult education courses should have its most imminent effect in the year after participation, naturally human capital investments during adulthood might also entail long-term effects. In particular, longterm effects might exceed the returns in the short run if participation in adult education is continuous rather than nonrecurring. Clearly, one hope of policy makers is that "adult

\footnotetext{
${ }^{12}$ Nonlinear second-stage estimates with continuous or multi-valued regressors require a correctly specified functional form in order to interpret the estimates easily. We, therefore, apply a 2SLS procedure although the dependent variable is binary. Even if the underlying second-stage relationship is nonlinear, 2SLS typically captures an average effect of economic interest analogous to the LATE parameter for dummy endogenous regressors (Angrist and Imbens, 1995).
} 
education begets adult education". In other words, the voucher might bring individuals into adult education, who will subsequently continue to invest in their human capital. This could be the case if imperfect information about the returns to adult education leads to a suboptimal private investment in adult education. If individuals learn about the true returns by participating once, subsequent investment decisions might by positively affected by voucherinduced participation in 2006. In this case, long-term effects of voucher-induced adult education might well exceed effects measured in the short run.

While we do not have information on labor market outcomes beyond 2007, we can analyze effects on the participation in adult education in 2007. Participation in 2007 is not directly affected by the voucher, because the voucher was only valid in 2006 . Hence, any effect of the voucher on future adult education probabilities must be caused by voucher-induced adult education in 2006.

As the results of Table 6 reveal, participation in adult education is indeed highly persistent. Estimates in column 1 show that 40 percent of the individuals who participated in selffinanced adult education in 2006 continue to participate in adult education in 2007 (after controlling for gender, age, and nationality). Adding further covariates to the model slightly reduces the coefficient to 0.36 (column 3).

Part of the observed correlation between adult education in 2006 and in 2007 might simply reflect habit formation or might be caused by adult education modules lasting for more than one year. To control for such confounding factors, we add participation in adult education in 2005 to the model. The results presented in column 4 of Table 6 show that the coefficient on adult education in 2006 is further reduced to 0.28 . The effect remains, however, large and statistically highly significant.

Does this imply that we can indeed expect voucher-induced adult education to lead to subsequent private human capital investments? To answer this question, we instrument selffinanced adult education in 2006 by voucher receipt. Column 6 of Table 6 shows the results of this IV estimation. The estimated effect of adult education in 2006 on adult education in 2007 is 0.13 and statistically insignificant. The standard errors are, however, again large. The effect, albeit not statistically significant, might thus still be economically significant. The point estimate suggests that the probability of subsequent private investment in adult education is raised by 13 percentage points through voucher-induced adult education in 2006 . This is, however, well below the estimated association between adult education in 2006 and subsequent adult education in columns 1 to 4 . Despite the somewhat low precision of the IV estimate, we can even statistically reject the large effects found in the OLS estimations. 
Column 7 reports the corresponding reduced-form estimate of receiving a voucher in 2006 on participation in adult education in 2007. The effect is statistically insignificant with a point estimate of 0.015 , corresponding to the IV estimate multiplied by the first-stage coefficient. A careful interpretation of these results concludes that, while small positive effects of the voucher on subsequent private investments in adult education cannot be statistically rejected, the effects are certainly not as high as suggested by estimated effects based on models controlling for large sets of background characteristics.

Summing up, the results suggest a pessimistic view on the effectiveness of adult education vouchers. OLS estimates with different sets of controls indicate highly heterogeneous effects of adult education on labor market success in the population and highly selective participation in adult education. The IV estimates foster the concern that returns to voucher-induced adult education are close to zero in the short run. Voucher-induced adult education might entail small positive effects on subsequent private investments, but these effects are not of the magnitude suggested by cross-sectional OLS estimates.

\subsection{Effect Heterogeneity}

The variation in the estimates of the effect of adult education on labor market success based on models with different sets of controls points to the existence of very heterogeneous effects of adult education in the population. We begin the analysis of heterogeneous effects by estimating ITT effects for vouchers of different face values. Next, we investigate associations between adult education and labor market success for selected subsets of the entire population suggested in OLS models. We additionally analyze potential variation in the estimated ITT effects for these different sub-populations.

Vouchers with three different face values were randomly rotated within the treatment group: 200, 750, and 1,500 Swiss francs, respectively. Table 7 reports estimates of the ITT effects separately for the three face values. While the pattern of point estimates in the first column is consistent with a lower pick-up rate for vouchers with the low face value, results do not differ significantly between the different face values. Similarly, the pattern of point estimates in the subsequent columns points to a weak positive association of face values with labor market effects, but results are statistically insignificant and close to zero even for the vouchers with the highest face value.

Table 8 reports estimated associations between our three labor market outcomes of interest and participation in adult education in 2006 for different sub-populations. The estimates are based on estimating equation (2), which includes pre-treatment controls, by OLS. The results 
reveal that OLS estimates of the effects of adult education on future earnings and employment probabilities are stronger for women than for men. Moreover, returns to adult education in terms of future earnings are higher for individuals with low education than for individuals with high levels of educational attainments. The result is in line with theoretical models assuming decreasing private returns to human capital investments.

Table 9 reports estimated ITT effects for the different sub-populations. The first column visualizes differences in first-stage coefficients. Pick-up rates are higher for women than for men. The first-stage coefficient also appears to be increasing in the level of educational attainment. Estimated returns to voucher receipt in terms of earnings reveal a substantial variation between educational groups. While the point estimate is negative for individuals holding a non-academic tertiary or a university degree, the estimated returns for individuals with vocational training is positive and close to reaching statistical significance at the 10 percent level.

In sum, the sub-sample analysis suggests that significant effect heterogeneity is hidden behind the average effects analyzed in the previous sub-section. In particular, individuals with tertiary degrees appear to have above-average pick-up rates, but below-average returns to adult education. By contrast, individuals with vocational training as highest educational degree appear to benefit highly from participation in adult education, although vouchers are less likely to induce them to participate.

\subsection{Characterizing Compliers}

From a policy perspective, it is important to understand which group of individuals will change their participation decision in response to the adult education vouchers. In the LATE framework, these individuals are the compliers. Naturally, because there are always-takers, compliers cannot be individually identified. However, it is possible to describe the distribution of characteristics of the compliers. This characterization is important for policy makers as it shows who will be ultimately affected by voucher programs. This characterization might differ from the descriptive statistics presented in Section 3, as the group averages presented there refer to the entire treatment group, which includes also the always-takers and the never-takers. The latter populations are, however, not of direct interest from a policy perspective.

To characterize compliers based on the subset of Bernoulli-distributed characteristics, we can make use of the variation in the first stage across covariate groups, as shown in Angrist and Pischke (2009). Let $x_{1 i}$ be a characteristic analyzed in the previous sub-section, for 
example, a dummy indicating university graduates. The relative likelihood of a voucher complier to be a university graduate is given by the following calculation:

$$
\frac{P\left[x_{1 \mathrm{i}}=1 \mid D_{1 \mathrm{i}}>D_{0 \mathrm{i}}\right]}{P\left[x_{1 \mathrm{i}}=1\right]}=\frac{P\left[D_{1 \mathrm{i}}>D_{0 \mathrm{i}} \mid x_{1 \mathrm{i}}=1\right]}{P\left[D_{1 \mathrm{i}}>D_{0 \mathrm{i}}\right]}=\frac{E\left[D_{\mathrm{i}} \mid z_{\mathrm{i}}=1, x_{1 \mathrm{i}}=1\right]-E\left[D_{\mathrm{i}} \mid z_{\mathrm{i}}=0, x_{1 \mathrm{i}}=1\right]}{E\left[D_{\mathrm{i}} \mid z_{\mathrm{i}}=1\right]-E\left[D_{\mathrm{i}} \mid z_{\mathrm{i}}=0\right]}
$$

where $z_{i}=1$ indicates voucher receipt, $D_{1 i}$ denotes participation in adult education in case of voucher receipt, and $D_{0 i}$ denotes the counterfactual outcome of participation in adult education in case individual $i$ does not receive a voucher. That is, the relative likelihood that a complier has $x_{1 i}=1$ is given by the ratio of the first stage for individuals with $x_{1 i}=1$ to the overall first stage.

Average characteristics for compliers are reported in Table 10. The final column shows the relative likelihood compliers have the characteristic indicated in each row. It becomes apparent that women are more likely to comply with the voucher assignment than men. Moreover, individuals with higher educational degrees are also more likely to participate in adult education in response to receiving a voucher.

These findings - together with the evidence on heterogeneous effects - might explain the low estimates of average labor market returns of voucher-induced adult education, as it points to a highly selective use of the voucher. On the one hand, individuals with higher levels of education are more likely to comply with the voucher assignment. Highly educated individuals are typically well informed about the returns to education and potentially have easier access to firm-financed adult education. Thus, highly educated compliers with the voucher assignment might be a selected sub-population of all individuals with tertiary education that face low labor market returns to adult education. Moreover, if private returns to human capital investments are decreasing in the level of human capital, individuals with tertiary education might more generally face low labor market returns to adult education. Highly educated individuals might, however, draw direct utility from adult education, which does not necessarily materialize in terms of labor market outcomes. This could explain the rather high pick-up rates among individuals with tertiary education.

On the other hand, individuals with less schooling are also less likely to comply with the voucher assignment. The evidence on heterogeneous effects suggests, however, that individuals with lower levels of educational attainment gain the most from adult education. In particular, individuals with vocational training appear to largely benefit from voucher-induced adult education, but this group is under-represented in the group of compliers. 


\section{Conclusion}

In this paper, we evaluated the effects of a large-scale randomized field experiment that issued vouchers for adult education to a treatment group, but not to a randomly devised control group, in a large sample representative of the Swiss adult population. Apart from the specific literature on public-sector training programs targeted at unemployed individuals as part of active labor market policies, this is the first experimental evidence on the returns to adult education. By contrast, the extensive existing literature on returns to employer-provided adult education and training so far suffers from a lack of randomization. Our experiment sheds light on governments' ability to improve labor market outcomes through untargeted voucher programs aimed at expanding adult education.

We find no significant average labor market effects of the voucher program. In particular, using an IV approach that instruments adult education by voucher receipt, we find no significant average effects of voucher-induced participation in adult education in the first half of 2006 on earnings and employment in 2007. Unfortunately, the IV estimates lack precision, so we cannot reject the existence of small average effects. However, all IV point estimates are close to zero and well below corresponding OLS estimates of the effects of adult education.

Investigating voucher effects on subsequent adult education, we exclude the possibility that the large persistence in adult education implied by OLS estimation is causal. Small positive effects of voucher-induced adult education on subsequent human capital investments cannot be ruled out and are in fact suggested by the IV point estimates.

Estimated OLS effects of adult education decrease significantly when adding covariates and, in particular, lagged dependent variables - to the models. This indicates highly selective participation in adult education and highly heterogeneous returns to adult education, which may also be a cause for the relatively low statistical precision of our IV estimates of the average effect. A sub-group analysis reveals that especially individuals with low levels of educational attainment might benefit from participating in adult education. A characterization of the complier population shows, however, that predominately individuals with higher levels of educational attainment take up the voucher option to participate in adult education.

These findings are relevant for guiding policies that try to promote adult education by voucher programs. The results cast strong doubt that voucher programs that are neither targeted at specific groups nor restricted to specific uses are effective in improving labor market outcomes. In particular, the potential of voucher programs to generate large positive average effects on labor market outcomes is questionable. In addition, the characterization of 
the group of compliers is helpful in a policy perspective. Only the complying individuals will change their participation decision in adult education in response to a voucher program. In the case of an untargeted voucher program, the voucher will mainly affect the behavior of highly educated individuals. This population might, however, not be the primary target for government interventions in the adult education market. Our results suggest that individuals with lower levels of educational attainment might benefit more from voucher-induced adult education. A specifically designed and targeted voucher program might, therefore, potentially generate larger effects on subsequent labor market success.

Methodologically, targeted program implementation may also help yield higher statistical precision of effect estimates in a setting characterized by serious effect heterogeneity. The relatively low statistical precision of our IV estimates despite the substantial sample size indicates that, due to effect heterogeneity, evaluations need either very large samples, must be restricted to more homogenous choice sets for adult education courses, or must be targeted to groups with more homogeneous effects in order to yield precise statistical estimates of the effects. 


\section{References}

Angrist, J.D. and Imbens, G.W. (1995). Two-stage least squares estimation of average causal effects in models with variable treatment intensity. Journal of the American Statistical Association, 90(430):431-442.

Angrist, J.D. and Krueger, A.B. (2001). Instrumental variables and the search for identification: From supply and demand to natural experiments. Journal of Economic Perspectives, 15(4):69-85.

Angrist, J.D. and Pischke, J.-S. (2009). Mostly Harmless Econometrics: An Empiricist's Companion. Princeton, NJ: Princeton University Press.

Barron, J.M., Berger, M.C., and Black, D.A. (1997). On-the-Job Training. Kalamazoo, MI: W.E. Upjohn Institute for Employment Research.

Bassanini, A., Booth, A.L., Brunello, G., De Paola, M., and Leuven, E. (2005). Workplace training in Europe. In Brunello, G., Garibaldi, P., and Wasmer, E., eds., Education and Training in Europe. Oxford: Oxford University Press.

Booth, A.L. and Bryan, M.L. (2005). Testing some predictions of human capital theory: New training evidence from Britain. Review of Economics and Statistics, 87(2): 391-394.

Bound, J., Jaeger, D.A., and Baker, R.M. (1995). Problems with instrumental variables estimation when the correlation between the instruments and the endogenous explanatory variable is weak. Journal of the American Statistical Association, 90:443-450.

Card, D. (1999). The causal effect of education on earnings. In Ashenfelter, O. and Card, D., eds., Handbook of Labor Economics, vol. 3A, pp. 1801-1863. Amsterdam: North Holland.

Card, D., Kluve, J., and Weber, A. (2010). Active labor market policy evaluations: A metaanalysis. Economic Journal, 120(548):F452-F477.

Cragg, J.G. and Donald, S.G. (1993). Testing identifiability and specification in instrumental variable models. Econometric Theory, 9(2):222-240.

Cunha, F. and Heckman, J. (2007). The technology of skill formation. American Economic Review, 97(2):31-47.

de Luna, X., Stenberg, A., and Westerlund, O. (2011). Can adult education delay retirement from the labour market? Journal of Population Economics, forthcoming. 
Frazis, H. and Loewenstein, M.A. (2005). Reexamining the returns to training: Functional form, magnitude, and interpretation. Journal of Human Resources, 40(2):453-476.

Greenberg, D. and Shroder, M. (2010). The Digest of Social Experiments. $3^{\text {rd }}$ edition. Washington, D.C.: The Urban Institute Press.

Hall, A.R., Rudebusch, G.D., and Wilcox, D.W. (1996). Judging instrument relevance in instrumental variables estimation. International Economic Review, 37(2):283-298.

Harrison, G.W. and List, J.A. (2004). Field experiments. Journal of Economic Literature, 42(4):1009-1055.

Heckman, J.J., LaLonde, R., and Smith, J. (1999). The economics and econometrics of active labor market programs. In Ashenfelter, O. and Card, D., eds., Handbook of Labor Economics, vol. 3A, pp. 1865-2097. Amsterdam: North Holland.

Heinrich, C.J., Mueser, P.R., Troske, K.R., Jeon, K.-S., and Kahvecioglu, D.C. (2009). New estimates of public employment and training program net impacts: A nonexperimental evaluation of the Workforce Investment Act program. La Follette School Working Paper 2009-013. Madison, WI: University of Wisconsin-Madison.

Imbens, G.W. and Angrist, J.D. (1994). Identification and estimation of local average treatment effects. Econometrica, 62(2):467-475.

Jacobson, L., LaLonde, R.J., and Sullivan, D.G. (2005). Estimating the returns to community college schooling for displaced workers. Journal of Econometrics, 125(1-2):271-304.

Kling, J.R., Liebman, J.B., and Katz, L.F. (2007). Experimental analysis of neighborhood effects. Ecomometrica, 75(1):83-119.

LaLonde, R.J. (1986). Evaluating the econometric evaluations of training programs with experimental data. American Economic Review, 76(4):604-620.

Lechner, M., and Wunsch, C. (2009). Are training programs more effective when unemployment is high? Journal of Labor Economics, 27(4):653-692.

Leigh, D.E. and Gill, A.M. (1997). Labor market returns to community colleges: Evidence for returning adults. Journal of Human Resources, 32(2):334-353.

Leuven, E. and Oosterbeek, H. (2008). An alternative approach to estimate the wage returns to private-sector training. Journal of Applied Econometrics, 23(4):423-434. 
McCall, B. and Smith, J. (2009). Adult education. Presentation at the conference on the Handbook of the Economics of Education (Hanushek, E.A., Machin, S., and Woessmann, L., eds.), September 3-5, Munich: CESifo.

Messer, D. and Wolter, S.C. (2009). Money matters: Evidence from a large-scale randomized field experiment with vouchers for adult training. CESifo Working Paper 2548. Munich: CESifo.

Mincer, J.A. (1974). Schooling, Experience, and Earnings. NBER Books. NBER Press: New York.

OECD (2004). Co-Financing Lifelong Learning: Towards a Systemic Approach. Paris: Organisation for Economic Co-operation and Development.

OECD (2005). Promoting Adult Learning. Paris: Organisation for Economic Co-operation and Development.

Peterson, P.E., Howell, W.G., Wolf, P.J., and Campbell, D.E. (2003). School vouchers: Results from randomized experiments. In Hoxby, C.M., ed., The Economics of School Choice, pp. 107-144. Chicago, IL: University of Chicago Press.

Pischke, J.-S. (2001). Continuous training in Germany. Journal of Population Economics, $14(3): 523-548$

Rouse, C.E. (1998). Private school vouchers and student achievement: An evaluation of the Milwaukee Parental Choice Program. Quarterly Journal of Economics, 113(2):553-602.

Stenberg, A. (2011). An evaluation of publicly provided formal education for low skilled with longitudinal data. Economics of Education Review, forthcoming.

Stenberg, A. and Westerlund, O. (2008). Does comprehensive education work for the longterm unemployed? Labour Economics, 15(1):54-67.

Stock, J.H., Wright, J.H., and Yogo, M. (2002). A survey of weak instruments and weak identification in generalized method of moments. Journal of Business \& Economic Statistics, 20(4):518-529.

Stock, J.H. and Yogo, M. (2005). Testing for weak instruments in linear IV regression. In Andrews, D.W.K. and Stock, J.H., eds., Identification and Inference for Econometric Models: Essays in Honor of Thomas Rothenberg, pp. 80-108. New York: Cambridge University Press. 
Table 1: Comparison of Means for Socio-demographic Characteristics in 2005

\begin{tabular}{lccl}
\hline \hline Variable & Treatment group & Control group & Difference \\
\hline Adult education in 2005 & .448 & .427 & .021 \\
Woman & .555 & .542 & .013 \\
Swiss & .877 & .837 & $.040^{* * *}$ \\
Age in 2005 & 41.3 & 41.6 & -.258 \\
Single parent & .068 & .063 & .004 \\
Children of the age $<5$ & .155 & .162 & -.007 \\
Compulsory education & .143 & .156 & -.012 \\
Vocational education & .504 & .470 & $.034^{* * *}$ \\
University entrance diploma & .089 & .092 & -.003 \\
Non-academic tertiary & .162 & .150 & .011 \\
University & .102 & .132 & $-.030^{* * *}$ \\
Not gainfully employed & .167 & .171 & -.005 \\
\hline Number of observations & 2,437 & 17,234 & \\
\hline \hline
\end{tabular}

Note: Data source: Swiss Labor Force Survey (SLFS) combined with data specifically collected in connection with the voucher experiment, which was conducted in 2006. Sample: all observations in 2005.

Table 2: Comparison of Means for Socio-demographic Characteristics in 2007

\begin{tabular}{lccc}
\hline \hline Variable & Treatment group & Control group & Difference \\
\hline Adult education in 2005 & .465 & .433 & $.032^{* *}$ \\
Woman & .560 & .559 & .001 \\
Swiss & .912 & .863 & $.049^{* * *}$ \\
Age in 2007 & 44.1 & 44.2 & -.080 \\
Married & .616 & .606 & .010 \\
Children of age $<5$ & .148 & .155 & -.008 \\
Compulsory education & .111 & .141 & $-.030^{* * *}$ \\
Vocational education & .479 & .471 & .008 \\
University entrance diploma & .094 & .083 & .011 \\
Non-academic tertiary & .203 & .161 & $.042^{* * *}$ \\
University & .114 & .144 & $-.030^{* * *}$ \\
\hline Number of observations & 1,422 & 9,099 & \\
\hline \hline
\end{tabular}

Note: Data source: Swiss Labor Force Survey (SLFS) combined with data specifically collected in connection with the voucher experiment, which was conducted in 2006. Sample: all observations in 2007 with non-missing information on adult education in 2006 (estimation sample). 
Table 3: Comparison of Means for Outcome Variables

\begin{tabular}{lccc}
\hline \hline Variable & Treatment group & Control group & Difference \\
\hline Adult education in 2006 & .448 & .328 & $.120^{* * *}$ \\
& $(.497)$ & $(.469)$ & \\
$\hookrightarrow$ at least one course self-financed & .328 & .180 & $.148^{* * *}$ \\
$\quad$ Self-financed adult education in 2006) & $(.470)$ & $(.384)$ & \\
$\hookrightarrow$ all courses firm-financed & .120 & .148 & $-.028^{* * *}$ \\
$\quad$ (Firm training in 2006) & $(.325)$ & $(.355)$ & \\
Gross hourly earnings in 2007 & 39.5 & 39.5 & .020 \\
Employment probability in 2007 & $(16.6)$ & $(16.4)$ & \\
& .848 & .831 & .017 \\
Adult education in 2007 & $(.359)$ & $(.375)$ & \\
& .461 & .421 & $.040 * * *$ \\
\hline \hline
\end{tabular}

Note: Data source: Swiss Labor Force Survey (SLFS) combined with data specifically collected in connection with the voucher experiment, which was conducted in 2006. Sample: all observations in 2007 with non-missing information on adult education in 2006 (estimation sample). Earnings are measured in Swiss francs. Standard deviations in parentheses. 
Table 4: Earnings Estimates

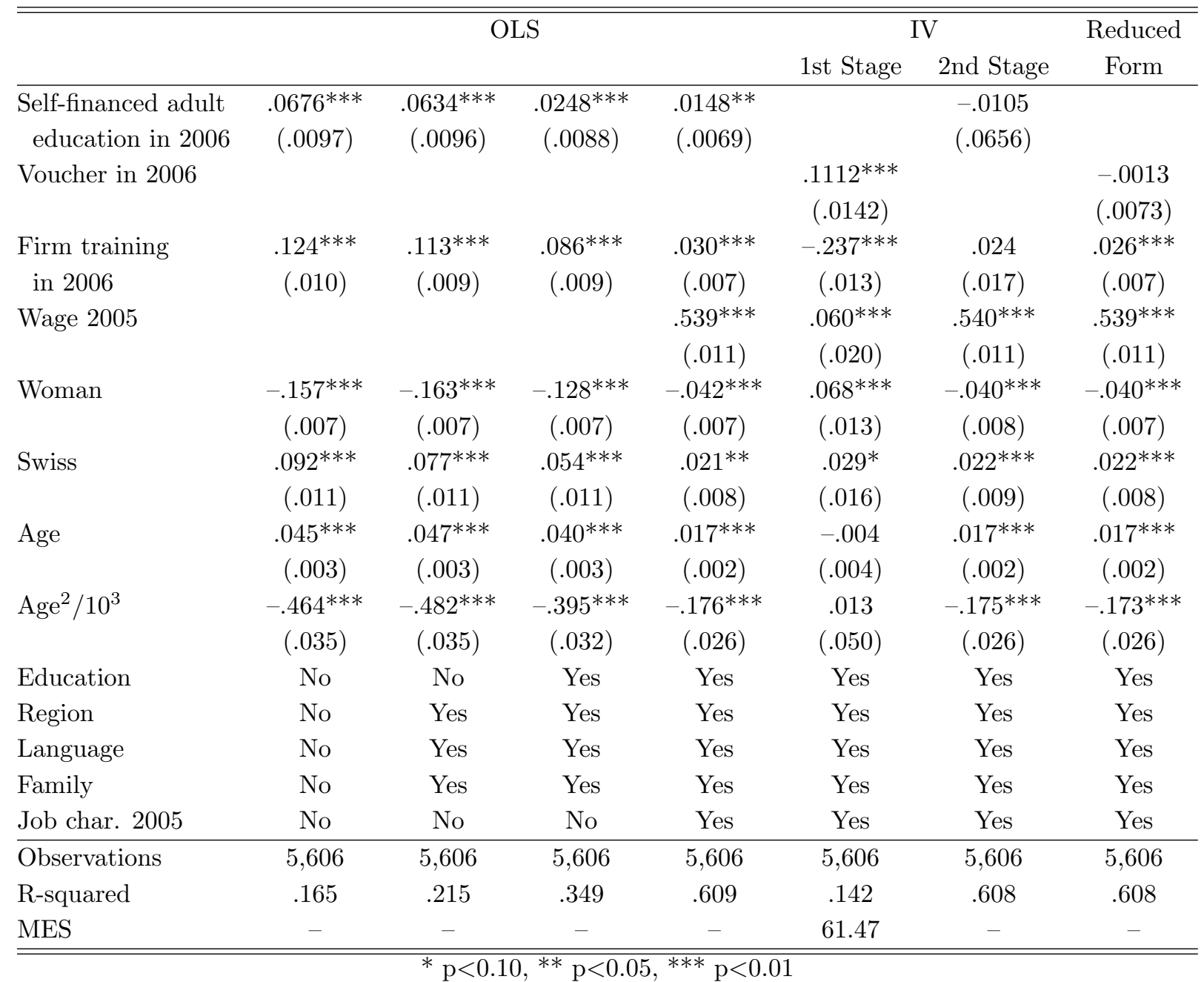

Note: Dependent variable: log gross hourly earnings in 2007. Standard errors in parentheses. Education controls include indicators for non-academic tertiary degree, vocational education, university entrance diploma, compulsory education, and university degree. Regional controls include 26 dummies for state of residence. Family controls include household size and indicators for being married, being divorced, and the number of children under 5. Job characteristics in 2005 include tenure as well as dummy variables for self-employment, part-time work, having a side job, 3 firm size categories, and industry based on 12 NOGA categories. MES refers to the Cragg and Donald (1993) minimum eigenvalue statistic. Data source: Swiss Labor Force Survey (SLFS) combined with data specifically collected in connection with the voucher experiment, which was conducted in 2006. 
Table 5: Employment Estimates

\begin{tabular}{|c|c|c|c|c|c|c|c|}
\hline & \multicolumn{4}{|c|}{ OLS } & \multicolumn{2}{|c|}{ IV } & \multirow{2}{*}{$\begin{array}{l}\text { Reduced } \\
\text { Form }\end{array}$} \\
\hline & & & & & 1st Stage & 2nd Stage & \\
\hline $\begin{array}{l}\text { Self-financed adult } \\
\text { education in } 2006\end{array}$ & $\begin{array}{l}.0800^{* * *} \\
(.0090)\end{array}$ & $\begin{array}{l}.0642^{* * *} \\
(.0089)\end{array}$ & $\begin{array}{l}.0499^{* * *} \\
(.0090)\end{array}$ & $\begin{array}{l}.0205^{* * *} \\
(.0072)\end{array}$ & & $\begin{array}{l}.0001 \\
(.0667)\end{array}$ & \\
\hline Voucher in 2006 & & & & & $\begin{array}{l}.120^{* * *} \\
(.0108)\end{array}$ & & $\begin{array}{l}.00001 \\
(.0080)\end{array}$ \\
\hline $\begin{array}{l}\text { Firm training } \\
\text { in } 2006\end{array}$ & $\begin{array}{l}.147^{* * *} \\
(.010)\end{array}$ & $\begin{array}{l}.133^{* * *} \\
(.010)\end{array}$ & $\begin{array}{c}.120^{* * *} \\
(.010)\end{array}$ & $\begin{array}{c}.031^{* * *} \\
(.008)\end{array}$ & $\begin{array}{c}-.258^{* * *} \\
(.011)\end{array}$ & $\begin{array}{l}.025 \\
(.019)\end{array}$ & $\begin{array}{c}.025^{* * *} \\
(.008)\end{array}$ \\
\hline Employed in 2005 & & & & $\begin{array}{c}.593^{* * *} \\
(.008)\end{array}$ & $\begin{array}{c}.055^{* * *} \\
(.010)\end{array}$ & $\begin{array}{l}.594^{* * *} \\
(.008)\end{array}$ & $\begin{array}{c}.594^{* * *} \\
(.008)\end{array}$ \\
\hline Woman & $\begin{array}{c}-.142^{* * *} \\
(.007)\end{array}$ & $\begin{array}{c}-.140^{* * *} \\
(.007)\end{array}$ & $\begin{array}{c}-.124^{* * *} \\
(.007)\end{array}$ & $\begin{array}{c}-.036^{* * *} \\
(.006)\end{array}$ & $\begin{array}{c}.106^{* * *} \\
(.008)\end{array}$ & $\begin{array}{c}-.034^{* * *} \\
(.009)\end{array}$ & $\begin{array}{c}-.034^{* * *} \\
(.006)\end{array}$ \\
\hline Swiss & $\begin{array}{c}.052^{* * *} \\
(.010)\end{array}$ & $\begin{array}{l}.013 \\
(.011)\end{array}$ & $\begin{array}{l}-.001 \\
(.011)\end{array}$ & $\begin{array}{l}-.006 \\
(.009)\end{array}$ & $\begin{array}{l}.048^{* * *} \\
(.012)\end{array}$ & $\begin{array}{l}-.005 \\
(.010)\end{array}$ & $\begin{array}{l}-.005 \\
(.009)\end{array}$ \\
\hline Age & $\begin{array}{c}.032^{* * *} \\
(.003)\end{array}$ & $\begin{array}{c}.039^{* * *} \\
(.003)\end{array}$ & $\begin{array}{c}.036^{* * *} \\
(.003)\end{array}$ & $\begin{array}{c}.016^{* * *} \\
(.002)\end{array}$ & $\begin{array}{l}.007^{* *} \\
(.003)\end{array}$ & $\begin{array}{c}.016^{* * *} \\
(.002)\end{array}$ & $\begin{array}{c}.016^{* * *} \\
(.002)\end{array}$ \\
\hline $\operatorname{Age}^{2} / 10^{3}$ & $\begin{array}{c}-.412^{* * *} \\
(.032)\end{array}$ & $\begin{array}{c}-.497^{* * *} \\
(.033)\end{array}$ & $\begin{array}{c}-.464^{* * *} \\
(.033)\end{array}$ & $\begin{array}{c}-.221^{* * *} \\
(.026)\end{array}$ & $\begin{array}{c}-.098^{* * *} \\
(.036)\end{array}$ & $\begin{array}{c}-.223^{* * *} \\
(.027)\end{array}$ & $\begin{array}{c}-.223^{* * *} \\
(.026)\end{array}$ \\
\hline Education & No & No & Yes & Yes & Yes & Yes & Yes \\
\hline Region & No & Yes & Yes & Yes & Yes & Yes & Yes \\
\hline Language & No & Yes & Yes & Yes & Yes & Yes & Yes \\
\hline Family & No & Yes & Yes & Yes & Yes & Yes & Yes \\
\hline Observations & 10,521 & 10,521 & 10,521 & 10,521 & 10,521 & 10,521 & 10,521 \\
\hline R-squared & .088 & .114 & .124 & .446 & .119 & .445 & .445 \\
\hline MES & - & - & - & - & 122.52 & - & - \\
\hline
\end{tabular}

Note: Dependent variable: employment dummy in 2007. Standard errors in parentheses. Education controls include indicators for non-academic tertiary degree, vocational education, university entrance diploma, compulsory education, and university degree. Regional controls include 26 dummies for state of residence. Family controls include household size and indicators for being married, being divorced, and the number of children under 5. MES refers to the Cragg and Donald (1993) minimum eigenvalue statistic. Data source: Swiss Labor Force Survey (SLFS) combined with data specifically collected in connection with the voucher experiment, which was conducted in 2006. 
Table 6: Estimates for Subsequent Adult Education

\begin{tabular}{|c|c|c|c|c|c|c|c|}
\hline & & $\mathrm{O}$ & & & & & Reduced \\
\hline & & & & & 1st Stage & 2nd Stage & Form \\
\hline $\begin{array}{l}\text { Self-financed adult } \\
\text { education in } 2006\end{array}$ & $\begin{array}{l}.397^{* * *} \\
(.011)\end{array}$ & $\begin{array}{l}.382^{* * *} \\
(.011)\end{array}$ & $\begin{array}{l}.354^{* * *} \\
(.011)\end{array}$ & $\begin{array}{l}.284^{* * *} \\
(.012)\end{array}$ & & $\begin{array}{c}.127 \\
(.108)\end{array}$ & \\
\hline Voucher in 2006 & & & & & $\begin{array}{c}.117^{* * *} \\
(.011)\end{array}$ & & $\begin{array}{l}.015 \\
(.013)\end{array}$ \\
\hline $\begin{array}{l}\text { Firm Training } \\
\text { in } 2006\end{array}$ & $\begin{array}{l}.405^{* * *} \\
(.013)\end{array}$ & $\begin{array}{l}.392^{* * *} \\
(.013)\end{array}$ & $\begin{array}{l}.369^{* * *} \\
(.013)\end{array}$ & $\begin{array}{l}.291^{* * *} \\
(.013)\end{array}$ & $\begin{array}{c}-.304^{* * *} \\
(.010)\end{array}$ & $\begin{array}{l}.242^{* * *} \\
(.036)\end{array}$ & $\begin{array}{l}.204^{* * *} \\
(.013)\end{array}$ \\
\hline $\begin{array}{l}\text { Adult education } \\
\text { in } 2005\end{array}$ & & & & $\begin{array}{l}.227^{* * *} \\
(.009)\end{array}$ & $\begin{array}{l}.203^{* * *} \\
(.008)\end{array}$ & $\begin{array}{l}.259^{* * *} \\
(.024)\end{array}$ & $\begin{array}{l}.285^{* * *} \\
(.009)\end{array}$ \\
\hline Woman & $\begin{array}{l}-.001 \\
(.009)\end{array}$ & $\begin{array}{l}.003 \\
(.009)\end{array}$ & $\begin{array}{l}.026^{* * *} \\
(.009)\end{array}$ & $\begin{array}{l}.022^{* *} \\
(.009)\end{array}$ & $\begin{array}{l}.088^{* * *} \\
(.007)\end{array}$ & $\begin{array}{l}.036^{* * *} \\
(.013)\end{array}$ & $\begin{array}{c}.048^{* * *} \\
(.009)\end{array}$ \\
\hline Swiss & $\begin{array}{l}.100^{* * *} \\
(.013)\end{array}$ & $\begin{array}{l}.068^{* * *} \\
(.014)\end{array}$ & $\begin{array}{l}.049^{* * *} \\
(.014)\end{array}$ & $\begin{array}{l}.039 * * * \\
(.014)\end{array}$ & $\begin{array}{l}.038^{* * *} \\
(.012)\end{array}$ & $\begin{array}{l}.046^{* * *} \\
(.015)\end{array}$ & $\begin{array}{c}.050^{* * *} \\
(.014)\end{array}$ \\
\hline Age & $\begin{array}{c}.020^{* * *} \\
(.004)\end{array}$ & $\begin{array}{c}.023^{* * *} \\
(.004)\end{array}$ & $\begin{array}{l}.021^{* * *} \\
(.004)\end{array}$ & $\begin{array}{c}.016^{* * *} \\
(.004)\end{array}$ & $\begin{array}{l}.004 \\
(.003)\end{array}$ & $\begin{array}{c}.017^{* * *} \\
(.004)\end{array}$ & $\begin{array}{c}.017^{* * *} \\
(.004)\end{array}$ \\
\hline $\mathrm{Age}^{2} / 10^{3}$ & $\begin{aligned}-.254^{* * *} \\
(.041)\end{aligned}$ & $\begin{array}{c}-.295^{* * *} \\
(.042)\end{array}$ & $\begin{array}{c}-.268^{* * *} \\
(.042)\end{array}$ & $\begin{array}{l}-.207^{* * *} \\
(.041)\end{array}$ & $\begin{array}{l}-.058^{*} \\
(.034)\end{array}$ & $\begin{array}{l}-.216^{* * *} \\
(.042)\end{array}$ & $\begin{array}{c}-.223^{* * *} \\
(.042)\end{array}$ \\
\hline Education & No & No & Yes & Yes & Yes & Yes & Yes \\
\hline Region & No & Yes & Yes & Yes & Yes & Yes & Yes \\
\hline Language & No & Yes & Yes & Yes & Yes & Yes & Yes \\
\hline Family & No & Yes & Yes & Yes & Yes & Yes & Yes \\
\hline Observations & 10,515 & 10,515 & 10,515 & 10,515 & 10,515 & 10,515 & 10,515 \\
\hline R-squared & .167 & .178 & .194 & .237 & .173 & .224 & .193 \\
\hline MES & - & - & - & - & 123.40 & - & - \\
\hline
\end{tabular}

Note: Dependent variable: adult education in 2007. Standard errors in parentheses. Education controls include indicators for non-academic tertiary degree, vocational education, university entrance diploma, compulsory education, and university degree. Regional controls include 26 dummies for state of residence. Family controls include household size and indicators for being married, being divorced, and the number of children under 5. MES refers to the Cragg and Donald (1993) minimum eigenvalue statistic. Data source: Swiss Labor Force Survey (SLFS) combined with data specifically collected in connection with the voucher experiment, which was conducted in 2006. 
Table 7: ITT Estimates by Face Value of the Voucher

\begin{tabular}{lcccc}
\hline \hline & $\begin{array}{c}\text { Self-financed } \\
\text { adult education } \\
\text { in } 2006\end{array}$ & $\begin{array}{c}\text { Earnings } \\
\text { in } 2007\end{array}$ & $\begin{array}{c}\text { Employed } \\
\text { in } 2007\end{array}$ & $\begin{array}{c}\text { Adult education } \\
\text { in } 2007\end{array}$ \\
\hline \hline 200 Swiss francs face value & $.102^{* * *}$ & -.011 & -.009 & -.010 \\
& $(.019)$ & $(.013)$ & $(.014)$ & $(.022)$ \\
\hline 750 Swiss francs face value & $.143^{* * *}$ & -.002 & -.003 & .029 \\
& $(.018)$ & $(.012)$ & $(.013)$ & $(.021)$ \\
\hline 1,500 Swiss francs face value & $.141^{* * *}$ & .008 & .011 & .023 \\
& $(.018)$ & $(.012)$ & $(.013)$ & $(.021)$ \\
\hline \hline & $* \mathrm{p}<0.10,{ }^{* *} \mathrm{p}<0.05,{ }^{* * *} \mathrm{p}<0.01$ &
\end{tabular}

Note: ITT estimates of having received a voucher in 2006 for subgroups of the voucher recipients defined by the face value of the voucher reported in the first column. The first row indicates the dependent variable. Standard errors in parentheses. The second column reports first-stage results by subgroups based on the first-stage specification used in Table 6. Otherwise, specifications correspond to the specifications presented in the last column of Tables 4, 5, and 6. Data source: Swiss Labor Force Survey (SLFS) combined with data specifically collected in connection with the voucher experiment, which was conducted in 2006.

Table 8: OLS Estimates of Adult Education Effects by Subgroups

\begin{tabular}{lccc}
\hline \hline & $\begin{array}{c}\text { Earnings } \\
\text { in } 2007\end{array}$ & $\begin{array}{c}\text { Employed } \\
\text { in } 2007\end{array}$ & $\begin{array}{c}\text { Adult education } \\
\text { in } 2007\end{array}$ \\
\hline \hline Men & .0139 & .0154 & $.275^{* * *}$ \\
& $(.010)$ & $(.010)$ & $(.019)$ \\
\hline Women & $.0161^{*}$ & $.0219^{* *}$ & $.290^{* * *}$ \\
& $(.010)$ & $(.010)$ & $(.014)$ \\
\hline Compulsory education & $.0687^{* *}$ & .0401 & $.236^{* * *}$ \\
& $(.028)$ & $(.029)$ & $(.034)$ \\
\hline Vocational training & $.0250^{* *}$ & .0119 & $.319^{* * *}$ \\
& $(.009)$ & $(.011)$ & $(.017)$ \\
\hline University entrance diploma & .0283 & .0274 & $.233^{* * *}$ \\
& $(.032)$ & $(.028)$ & $(.038)$ \\
\hline Non-academic tertiary & -.00430 & .0170 & $.257^{* * *}$ \\
& $(.015)$ & $(.012)$ & $. .027)$ \\
\hline University & -.0130 & $.0295^{*}$ & $(.031)$ \\
& $(.021)$ & $(.016)$ & \\
\hline \hline
\end{tabular}

Note: Results report estimates for the effect of participating in self-financed adult education in 2006. The OLS estimates are reported for subgroups of the population defined by the characteristic reported in the first column. The first row indicates the dependent variable. Standard errors in parentheses. All estimates are based on the specifications reported in the fourth columns of Tables 4, 5, and 6. Data source: Swiss Labor Force Survey (SLFS) combined with data specifically collected in connection with the voucher experiment, which was conducted in 2006. 
Table 9: ITT Estimates of Voucher Effects by Subgroups

\begin{tabular}{lcccc}
\hline \hline & $\begin{array}{c}\text { Self-financed } \\
\text { adult education } \\
\text { in 2006 }\end{array}$ & $\begin{array}{c}\text { Earnings } \\
\text { in } 2007\end{array}$ & $\begin{array}{c}\text { Employed } \\
\text { in } 2007\end{array}$ & $\begin{array}{c}\text { Adult education } \\
\text { in } 2007\end{array}$ \\
\hline \hline Men & $.0973^{* * *}$ & -.00493 & .00413 & .0140 \\
& $(.015)$ & $(.009)$ & $(.010)$ & $(.019)$ \\
\hline Women & $.152^{* * *}$ & .00659 & -.00594 & .0142 \\
& $(.016)$ & $(.011)$ & $(.012)$ & $(.017)$ \\
\hline Compulsory education & $.0687^{* *}$ & -.0246 & .00436 & .0216 \\
& $(.025)$ & $(.027)$ & $(.028)$ & $(.033)$ \\
\hline Vocational training & $.115^{* * *}$ & .0151 & -.000421 & .00387 \\
& $(.015)$ & $(.009)$ & $(.012)$ & $(.019)$ \\
\hline University entrance diploma & $.154^{* * *}$ & .00674 & -.0160 & .00581 \\
& $(.040)$ & $(.032)$ & $(.032)$ & $(.044)$ \\
\hline Non-academic tertiary & $.176^{* * *}$ & -.0266 & -.000338 & .0220 \\
& $(.028)$ & $(.017)$ & $(.014)$ & $(.030)$ \\
\hline University & $.145^{* * *}$ & -.0186 & -.00158 & .00655 \\
& $(.035)$ & $(.028)$ & $(.021)$ & $(.040)$ \\
\hline \hline & $* \mathrm{p}<0.10,{ }^{* *} \mathrm{p}<0.05,{ }^{* * *} \mathrm{p}<0.01$ & &
\end{tabular}

Note: ITT estimates of having received a voucher in 2006 for subgroups of the population defined by the characteristic reported in the first column. The first row indicates the dependent variable. Standard errors in parentheses. The second column reports first-stage results by subgroups based on the first-stage specification used in Table 6. Otherwise, specifications correspond to the specifications presented in the last column of Tables 4, 5, and 6. Data source: Swiss Labor Force Survey (SLFS) combined with data specifically collected in connection with the voucher experiment, which was conducted in 2006 . 
Table 10: Characterizing Compliers

\begin{tabular}{lccc}
\hline \hline Variable & $P\left[x_{1 i}=1\right]$ & $P\left[x_{1 i}=1 \mid D_{1 i}>D_{0 i}\right]$ & $\begin{array}{c}P\left[x_{1 i}=1 \mid D_{1 i}>D_{0 i}\right] / \\
P\left[x_{1 i}=1\right]\end{array}$ \\
\hline Woman & 0.56 & 0.66 & 1.18 \\
Compulsory education & 0.14 & 0.07 & 0.54 \\
Vocational education & 0.47 & 0.42 & 0.89 \\
University entrance diploma & 0.08 & 0.10 & 1.17 \\
Non-academic tertiary & 0.17 & 0.23 & 1.37 \\
University & 0.14 & 0.16 & 1.14 \\
Age 20 to 29 & 0.12 & 0.06 & 0.54 \\
Age 30 to 39 & 0.26 & 0.19 & 0.76 \\
Age 40 to 49 & 0.29 & 0.37 & 1.30 \\
Age 50 to 60 & 0.28 & 0.32 & 1.15 \\
Employed in 2005 & 0.82 & 0.79 & 0.96 \\
Adult education in 2005 & 0.44 & 0.47 & 1.08 \\
\hline \hline
\end{tabular}

Note: The table reports an analysis of complier characteristics. The ratio in the last column shows the relative likelihood compliers have the characteristic indicated in each row. Data source: Swiss Labor Force Survey (SLFS) combined with data specifically collected in connection with the voucher experiment, which was conducted in 2006 . 
Figure 1: Wage Distributions by Year and Voucher Status
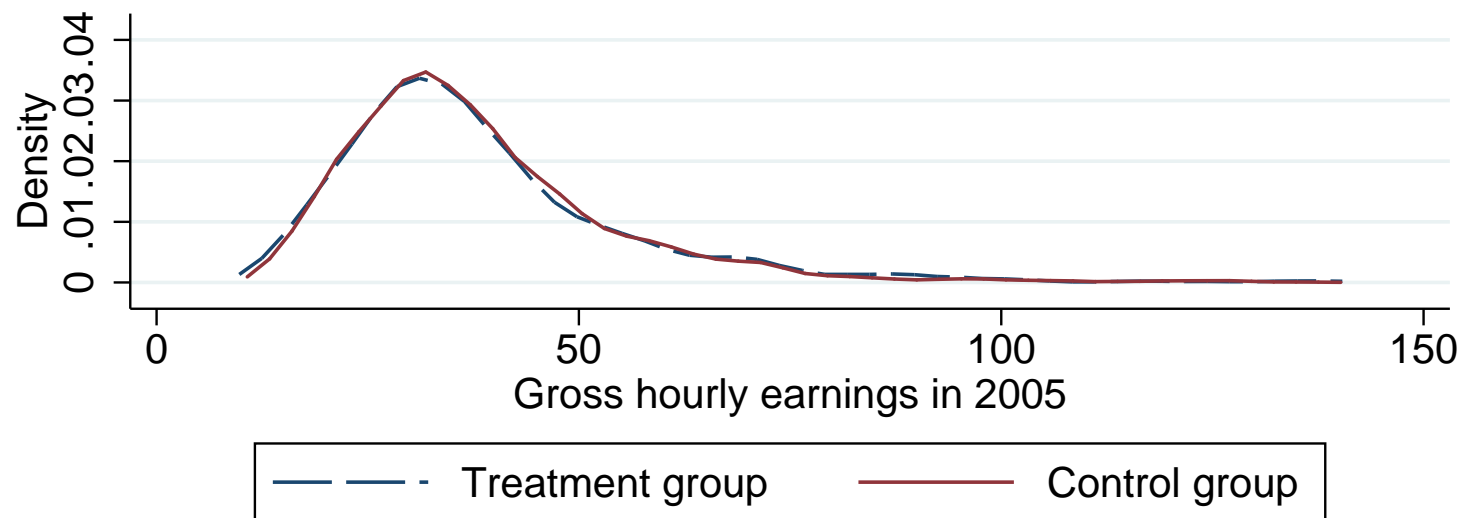

p-value: .94

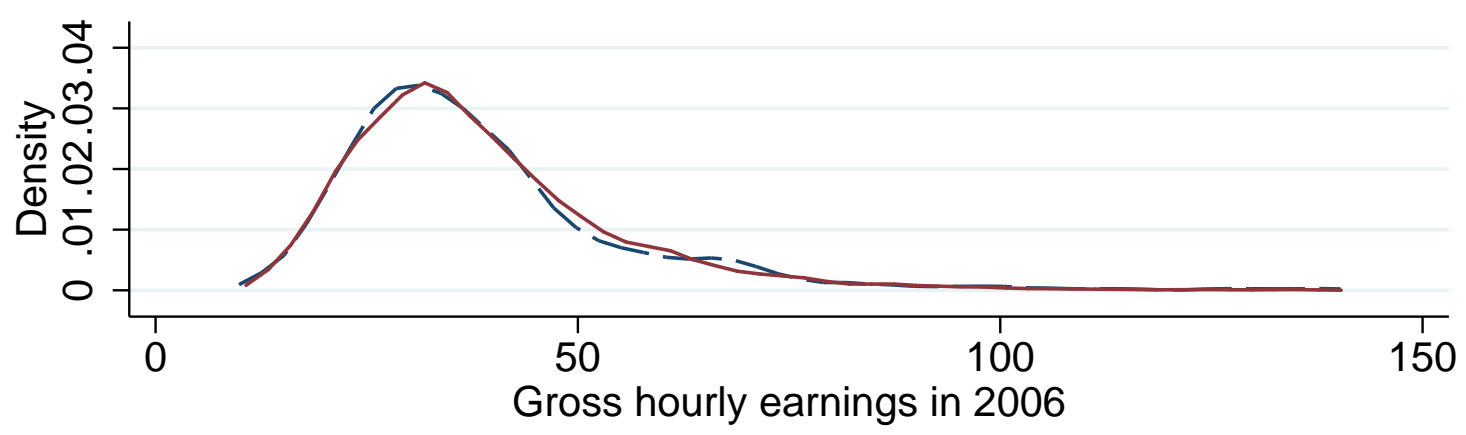

\section{- - - Treatment group $\longrightarrow$ Control group}

p-value: .56

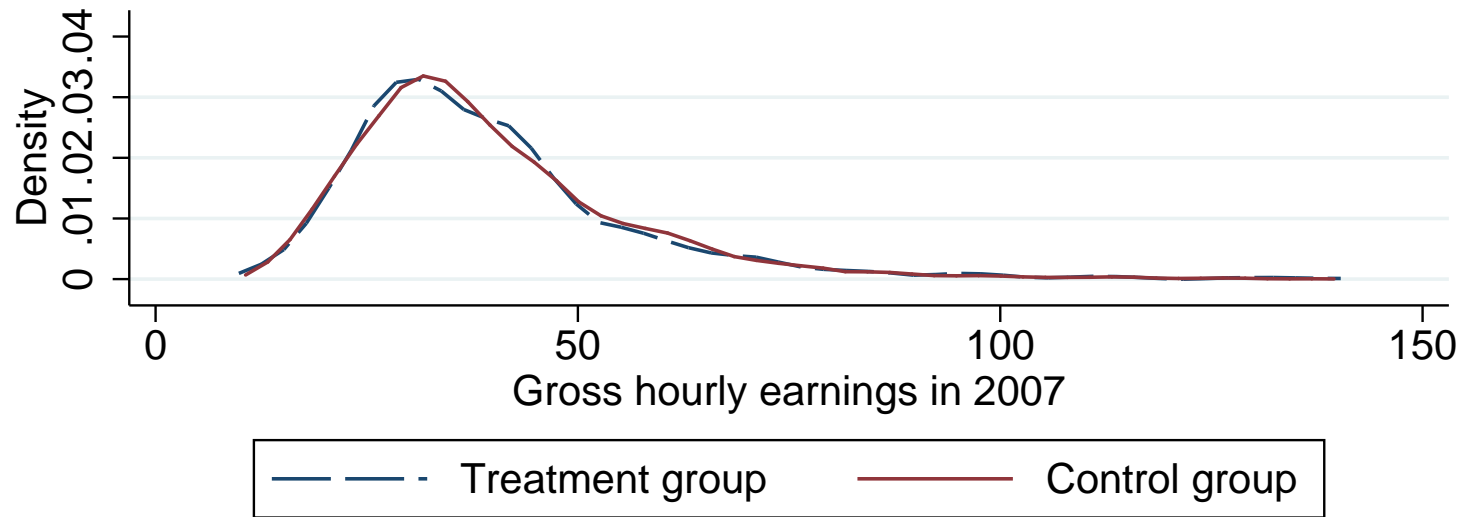

p-value: .57

Note: Kernel density estimates based on 2007 estimation sample. $p$-values refer to two-sample KolmogorovSmirnov tests of the equality of distributions. Data source: Swiss Labor Force Survey (SLFS) combined with data specifically collected in connection with the voucher experiment, which was conducted in 2006. 